\title{
Accuracy of lung ultrasound for the diagnosis of consolidations when compared to chest computed tomography
}

\author{
P Nazerian ${ }^{1 *}$, G Volpicelli ${ }^{2}$, S Vanni ${ }^{1}$, C Gigli ${ }^{1}, C$ Tozzetti ${ }^{1}$, A Petrioli ${ }^{1}$, S Grifoni ${ }^{1}$ \\ From 10th WINFOCUS World Congress on Ultrasound in Emergency and Critical Care \\ Kuala Lumpur, Malaysia. 16-19 November 2014
}

\section{Background}

Despite the emergence of evidences on the usefulness of lung ultrasound (LUS) for the diagnosis of pneumonia, to date societal guidelines still do not recommend the use of sonography to this purpose.

\section{Objective}

Our study assesses the accuracy of LUS for the diagnosis of lung consolidations when compared to chest compute tomography $(\mathrm{CT})$.

\section{Patients and nethods}

This was a prospective study on a population complaining of respiratory symptoms of unexplained origin in the emergency department, who underwent chest CT. LUS was blindly performed to assess the diagnosis of lung consolidations, and then compared with chest CT.

\section{Results}

We analyzed 285 consecutive patients. Chest CT was positive for at least one consolidation in 87 studies. LUS was feasible in all patients and in 81 showed at least one consolidation, with a good inter-observer agreement $(\mathrm{k}=0.83)$, sensitivity $82.8 \%$ (95\% CI 73.2-90) and specificity $95.5 \%$ (95\% CI 91.5-97.9). Sensitivity raised to $91.7 \%$ (95\% CI 61.5-98.6) and specificity to $97.4 \%$ (95\%CI $86.5-$ 99.6) in patients complaining of pleuritic chest pain. In a subgroup of 190 patients who underwent also chest radiography (CXR), the sensitivity of LUS $(81.4 \%$, 95\% CI 70.7-89.7) was significantly superior to CXR (64.3\%, 95\%CI 51.9-75.4) $(\mathrm{p}<0.05)$; whereas specificity remained

\footnotetext{
* Correspondence: pnazerian@hotmail.com

'Department of Emergency Medicine and 3Radiology Department, Careggi University Hospital, Firenze, Italy

Full list of author information is available at the end of the article
}

similar (94.2\%, 95\% CI 88.4-97.6 vs 90\%, 95\% CI 83.294.7).

\section{Conclusions}

LUS represents a reliable diagnostic tool alternative to CXR for the diagnosis of lung consolidations at bedside, in patients with respiratory complains.

\section{Authors' details}

${ }^{1}$ Department of Emergency Medicine and 3Radiology Department, Careggi University Hospital, Firenze, Italy. ${ }^{2}$ Department of Emergency Medicine, San Luigi Gonzaga University Hospital, Torino, Italy.

Published: 9 March 2015

doi:10.1186/2036-7902-7-S1-A13

Cite this article as: Nazerian et al:: Accuracy of lung ultrasound for the diagnosis of consolidations when compared to chest computed tomography. Critical Ultrasound Journal 2015 7(Suppl 1):A13.

Submit your manuscript to a SpringerOpen ${ }^{\circ}$ journal and benefit from:

- Convenient online submission

- Rigorous peer review

- Immediate publication on acceptance

- Open access: articles freely available online

- High visibility within the field

- Retaining the copyright to your article

Submit your next manuscript at $>$ springeropen.com (c) 2015 Nazerian et al; licensee Springer. This is an Open Access article distributed under the terms of the Creative Commons Attribution License (http://creativecommons.org/licenses/by/4.0), which permits unrestricted use, distribution, and reproduction in any medium, provided the original work is properly cited. 